\title{
Timber supply and economic impacts associated with sustained yield unit size
}

\author{
by K. B. Rouck and J. D. Nelson
}

\begin{abstract}
Partitioning the forest into sustained yield units is a complex task that involves assessing timber supply, allocation of cutting rights, and social, economic, and environmental impacts. There are numerous ways to vary the timing and intensity of harvests within individual drainages while still meeting the objectives of sustained yield. In this paper we use a spatial forest planning model to examine economic and environmental implications of varying the sustained yield unit size. Harvests for a Timber Supply Area in British Columbia are calculated using 4 sizes of sustained yield units: 1) 12 small units, 2) four moderately sized units 3) two large units, and 4) one unit representing the entire forest. Relative to the 12 small units, short-term ( 20 year) harvest levels for the Timber Supply Area increased by $7.6 \%, 10 \%$, and $10.8 \%$ for the 4,2 and 1 unit aggregations, respectively. Medium-(21-60 years) and long-term (61-120 years) increases in harvest levels averaged approximately $75 \%$ and $40 \%$, respectively, of those realized in the short-term. Reductions in the length of active road and delivered wood costs were also observed as sustained yield units increased in size. Small units often restrict short-term timber supply and provide continuous road access to important wildlife habitat. While larger units afford greater flexibility in meeting short-term harvests, the intensity of the harvest within individual drainages increases. However, with large units the inactive drainages can be closed for extended periods, thus limiting human access to the active drainages.
\end{abstract}

Key words: timber supply, sustained yield unit size, spatial modelling, economics
La division des forêts en unités à rendement soutenu constitue une tâche complexe comprenant l'estimation des volumes de matière ligneuse, de l'allocation des droits de coupe ainsi que des impacts sociaux économiques et environnementaux. Il existe plusieurs façons de varier la période et l'intensité de coupe prévue pour chaque bassin hydrographique tout en respectant les objectifs de rendement soutenu. Pour les fins de cet exposé, nous avons utilisé un modèle de planification spatiale des forêts afin d'examiner les implications économiques et environnementales découlant de chaque variation de la dimension des unités à rendement soutenu. Les récoltes d'un territoire d'approvisionnement en matière ligneuse situé en Colombie-Britannique sont calculées selon quatre dimensions d'unité à rendement soutenu: 1) douze petites unités, 2) quatre unités de dimension raisonnable, 3) deux grandes unités, et 4) une unité représentant une forêt entière. Les niveaux de récolte à court terme (20 ans) pour les douze petites unités situées sur le territoire d'approvisionnement en matière ligneuse ont augmenté de $7.6 \%$, de $10 \%$ pour les quatres unités, de $10.8 \%$ pour les 2 unités ainsi que la forêt entière. Les augmentations à moyen terme ( 21 à 60 ans) et à long terme (61 à 120 ans) des niveaux de récolte atteignaient en moyenne $75 \%$ et $40 \%$ respectivement, par rapport à ceux atteints à court terme. Des réductions de la longueur des chemins actifs et des coûts du bois livré ont été observés en fonction de l'augmentation de la dimension des unités à rendement soutenu. Les petites unités empêchent souvent l'approvisionnement à court terme et procure un accès continu par route à un important domaine faunique. Alors que les grandes unités offrent une plus grande flexibilité pour rencontrer les récoltes à court terme, l'intensité de la récolte augmente au sein de chaque unité à rendement soutenu. Toutefois, au sein des grandes unités, les bassins non utilisés peuvent être fermés pour de grandes périodes, limitant ainsi l'accessibilité humaine aux bassins en opération.

Mots clés: approvisionnement en matière ligneuse, dimension d'une unité à rendement soutenu, modélisation spatiale, principes économiques

\section{Introduction}

As public interest in British Columbia's forest resource reshapes traditional timber management practices, the current state of the forest inventory, as well as the methodology used to determine Annual Allowable Cuts (AACs) has come under considerable public scrutiny. In 1976, the Pearse Commission of Inquiry into Forest Policy called for the aggregation of existing Public Sustained Yield Units (PSYUs) to create large Timber Supply Areas (TSAs) designed to serve major manufacturing centers (Pearse 1976). As a result, AACs are now determined on large TSAs throughout the province, some that exceed 2 million ha. In the absence of area-specific harvest regulations, these large sustained yield units provide enormous flexibility for harvest scheduling. However, through the last decade, numerous watershed specific regulations (maximum disturbance rates for hydrology, retention of thermal cover for wildlife, etc.) were introduced, and whether large sustained yield

Department of Forest Resources Management, Faculty of Forestry, University of British Columbia, 270 - 2357 Main Mall, Vancouver, British Columbia, Canada V6T 1 Z4 units still offer such an advantage is questionable. Historically, cut-over watersheds and undisturbed watersheds were combined to produce uniform harvest flows, where the undisturbed watershed was harvested at a high rate until the cut-over watershed matured. Now, specific forest structures and landscape patterns must be maintained in every watershed, and opportunities to harvest one watershed at a high rate in order to offset age-class deficits elsewhere are limited.

The importance of managing forests for non-timber values such as water yields, recreational opportunities, wildlife habitat, and aesthetic values has changed the traditional forestry paradigms almost overnight. As a result, foresters must now attempt to ensure not only a sustainable supply of timber products, but must also demonstrate that ecosystem health is not compromised in the process. This is an enormous task, and it is forcing many practitioners towards detailed watershed level planning. To address the sustainability issue, these plans need to be spatially explicit and they must cover long time horizons. This planning process is ideal for managing individual watersheds on a sustained yield basis, but there are concerns that constraining harvest flows on individual units will negatively affect TSA harvest levels (BC Ministry of Forests 1991). 


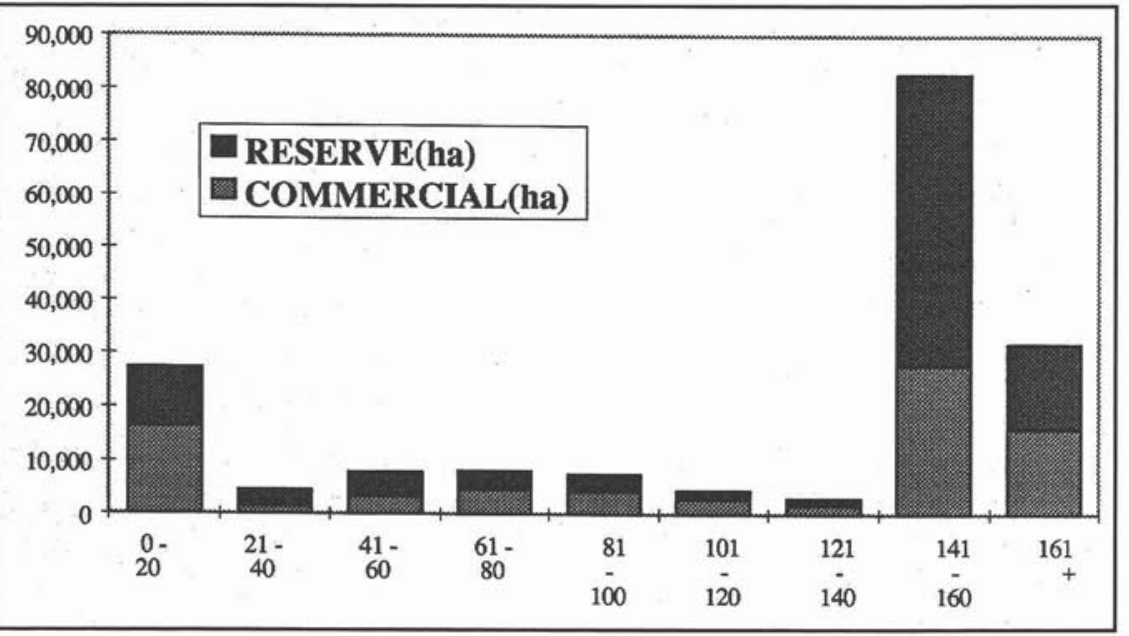

Figure 1. Summary of commercial and reserved areas in the Revelstoke TSA.
Similarly, managing each watershed within the TSA as a sustained yield unit may have negative environmental impacts because of increased accessibility to certain wildlife populations. Before the practice of managing each watershed in the landscape as an independent unit is adopted, the impacts of such widespread forestry activities on timber supply, wildlife populations and other non-timber values need to be assessed.

The purposes of this study are to determine the effect of sustained yield unit size on timber supply and economics, and to examine the associated environmental implications. The Revelstoke Timber Supply Area is used as a case study. The TSA is partitioned into 12 compartments, which are first treated as sustained yield units, and subsequently aggregated to create larger sustained yield units.

At each level of aggregation, a harvest schedule which maximizes short-term harvests is generated using a spatial forest planning model. Changes in timber supply, road network activity, and delivered wood costs are quantified at each level of aggregation. Possible ecological implications due to sustained yield unit size are also discussed.

This paper consists of five major sections. First, the forested landbase of the Revelstoke TSA is described. Second, the harvest rules and assumptions used in the harvest scheduling simulation are described, along with a brief overview of the computer model. Third, a description of the process used to create the sustained yield units and the methods used to compare harvest levels is presented. Fourth, results are presented and analyzed. Finally, important issues related to sustained yield unit size are identified and discussed.

\section{Study Area Description}

The Revelstoke TSA is located in the rugged, south-eastern region of British Columbia. The TSA supports a wide range of recreational and tourism needs; it forms a strategic connection between two National Parks, and supports a local forest products industry. The main forest cover types include spruce, balsam, hemlock, western red cedar, Douglas-fir, lodgepole pine, and western larch.

${ }^{1}$ This figure differs from that used by the BC Ministry of Forests (1993) in the Timber Supply Analysis of the Revelstoke TSA due to the difference in assumptions associated with commercial forest types. For the remainder of this paper, the areas reported will be those used in our spatial analysis.
Although the gross area of the TSA is in excess of 504000 ha, only 176945 ha of timber are considered to be of commercial quality. ${ }^{1}$ Major deductions from the total landbase are as follows: non-crown land (4\% of total area), non-forest land (56\%), and inoperable areas (22\%) (BC Ministry of Forests 1993). An additional $7 \%$ of the forested landbase is reserved as environmentally sensitive areas, non-merchantable forest types, riparian areas, and avalanche chutes. Once other miscellaneous deductions are accounted for, the total landbase available for harvesting is only $35 \%$ of the gross TSA area. Although all environmentally sensitive areas and inoperable blocks were designated as "reserve" status and are not eligible for harvest, they are included in the analysis because they contribute towards forest cover constraints. All commercial and reserved areas by ageclass were summarized (Fig. 1).

The data used in this study were compiled by the Revelstoke Forest District staff. Individual harvest units (or blocks) were located on 1:20,000 maps, and each block was assigned the following attributes: volume curve, silvicultural system, harvest system, initial age, and harvest zone. The data for the TSA included $14000^{+}$harvest units, $18000^{+}$road-links, 12 planning compartments, and 160 harvest zones.

\section{Simulation Model}

ATLAS is a computer simulation model used to examine shortand long-term effects of spatial harvesting restrictions and silvicultural treatments using a block-by-block approach, rather than the traditional strata-based approach used by other forest planning models (Nelson et al. 1995). As with other simulation models, the target harvest schedule must be found through iterative trials.

The largest geographic unit recognized by the model is the "planning compartment". Individual planning compartments can be subdivided into "zones" to which a unique harvesting rule can be applied. Rules like maximum disturbance rates and minimum forest cover requirements apply to individual zones. The smallest unit recognized by the model is the "harvest unit" (Fig. 2). Within the model, unique combinations of attributesblock area, volume/age curves, initial stand-age, silvicultural systems, harvest systems, and road links — are defined and assigned to individual harvest units. 

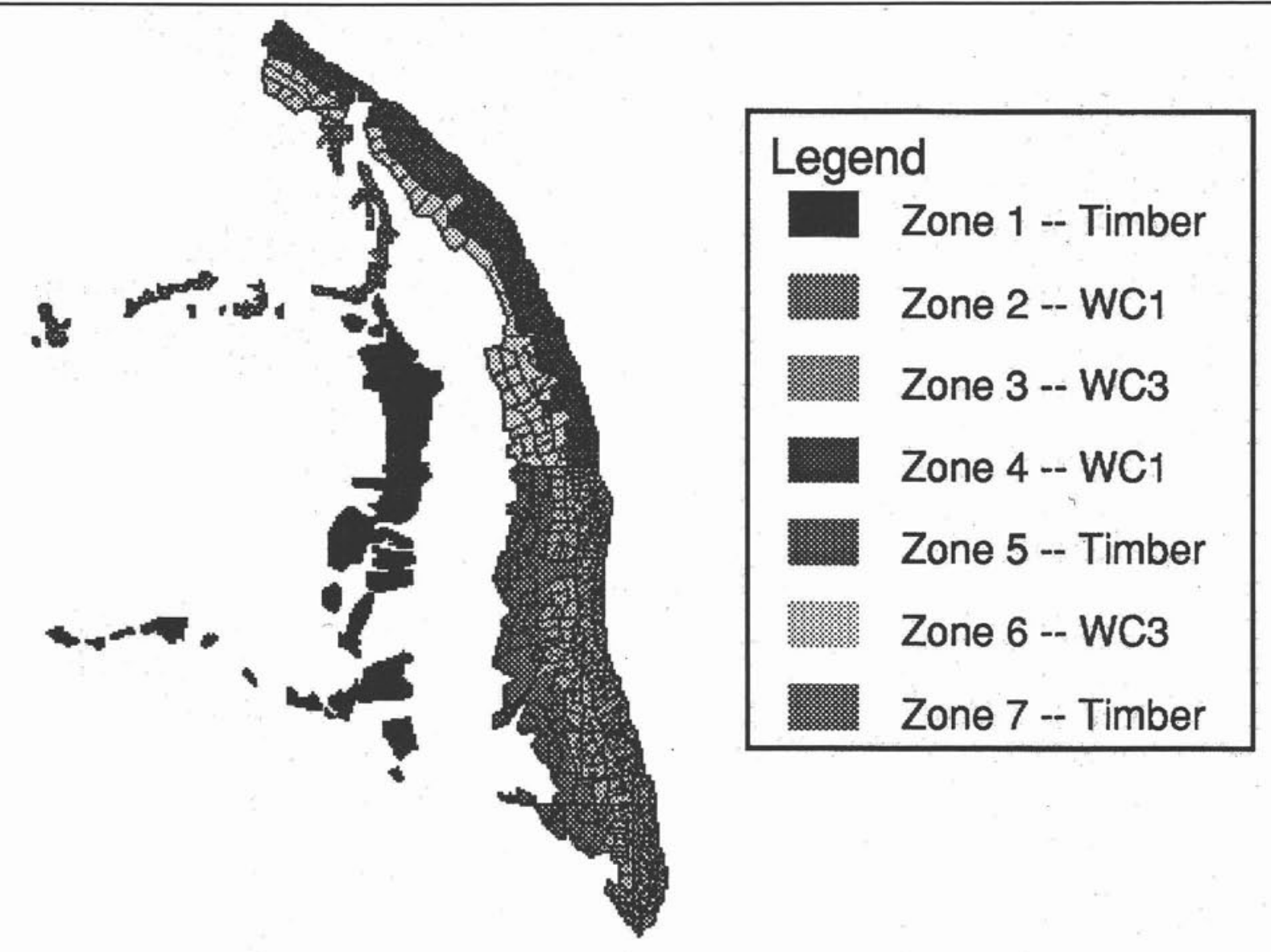

Figure 2. Planning compartment 5 , showing zones and harvest unit boundaries. Each zone represents a geographic area to which a specific harvest rule applies.

\section{Harvest Scheduling Algorithm}

When simulating a timber harvest, ATLAS schedules harvest units according to a "closest block first" algorithm designed to minimize the amount of road constructed in each period. Harvest priorities are assigned to the planning compartments, then to each zone within the compartments, and finally, to each harvest unit within each zone. In this study, compartments at the southern end of the TSA have the highest priority, and those at the northern end have the lowest priority. Zone priority is based on the distance to the centre of the zone from a pre-determined major road link in the planning compartment. Likewise, the harvest priority rating of each harvest unit is based on its distance from the major road link in the planning compartment. In each planning period, the model selects blocks for harvest by first going to the highest ranked planning compartment, then to highest ranked zone within that planning compartment, and finally to the highest ranked harvest unit within that zone. Harvest units are selected in successive zones until either the target harvest is reached, or until constraints become binding. The entire forest is then aged one period, and the harvesting cycle is repeated. The simulation terminates when the planning horizon has been reached.

\section{Harvest Rules}

All simulations use a planning horizon of 120-years (approximately one rotation) and a planning period of 10 -years. The harvest rules include adjacency and green-up, wildlife cover constraints, and visual quality restrictions. These rules are applied to the zones, which average 1100 ha in size. The harvest rules and the amount of the TSA area affected by each are summarized (Table 1).

\section{Harvest Flow Constraints}

Harvest levels were set to maximize short-term volume production, with a maximum $10 \%$ reduction per decade, until even-flow was reached. The decision to maximize short-term harvests is based partly on forest dynamics, and partly on current policy in the province. Changes in harvest levels associated with sustained yield unit size are largely, if not totally, a short-term phenomena. Over the long-term, in the presence of watershed level constraints, the forest reaches an equilibrium in age-classes and spatial patterns, and we would expect little or no gains to be realized by creating larger sustained yield units. However, in the short-term, age-class distributions and spatial patterns may be binding, and incremental gains in harvest levels may be realized by the additional scheduling flexibility offered by larger sustained yield units. By maximizing short-term volume production, we attempt to capture these incremental gains. Short-term volume maximization also helps to account for the fall-down effect which occurs as old-growth stands (high volume per ha) are converted to managed stands (low volume 
Table 1. Harvest rules used in the Revelstoke TSA. The percentage of area to which each rule applies is shown on the right.

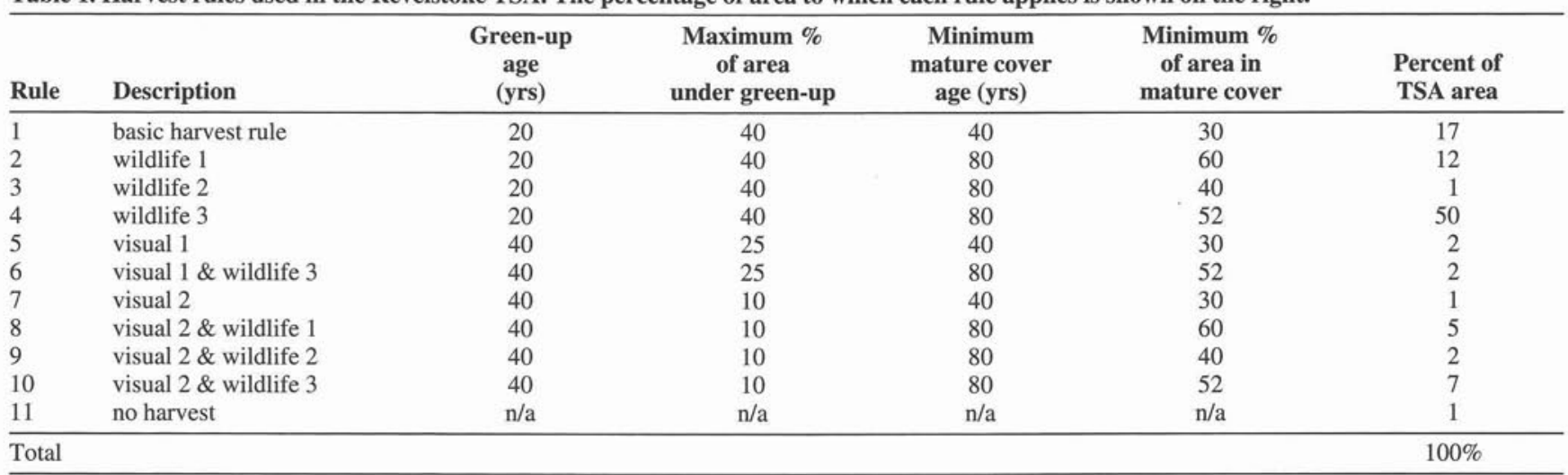

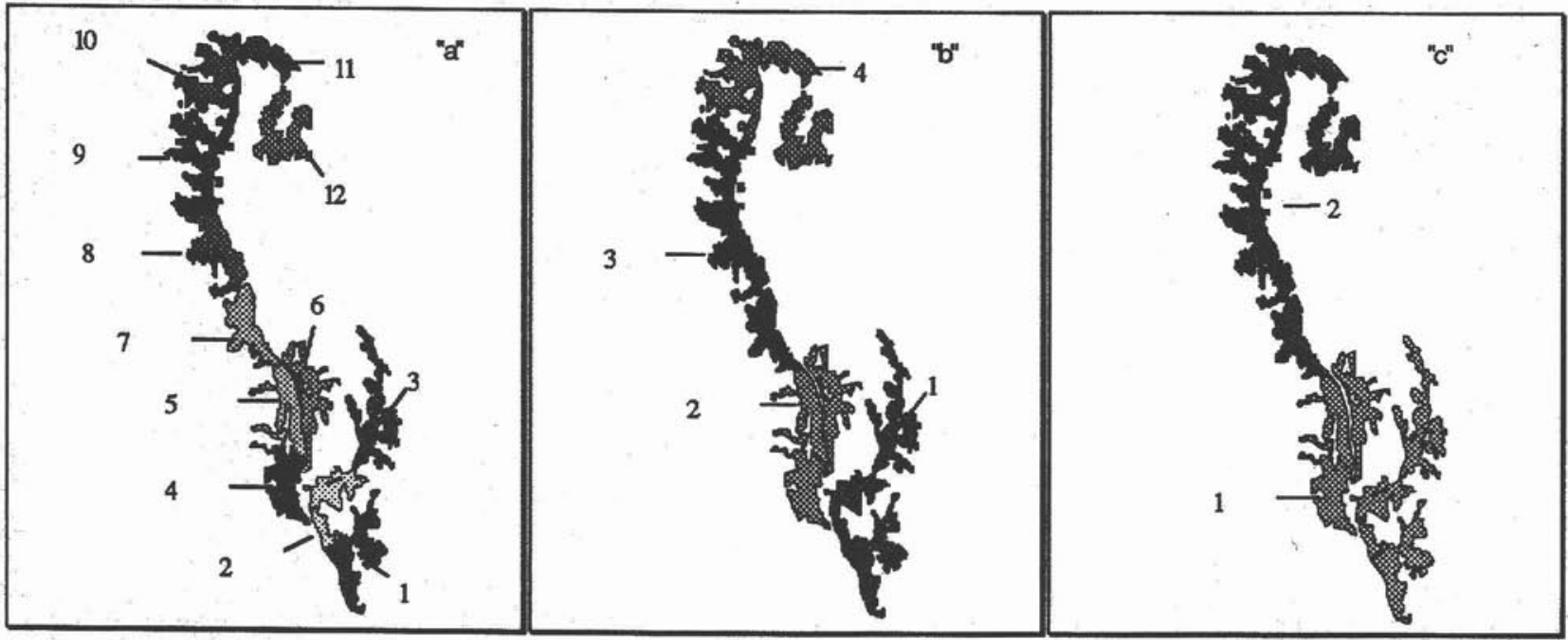

Figure 3. Forested area of the Revelstoke Timber Supply Area showing a) the 12 planning compartments, b) the four sustained yield units from the first level aggregation, and c) the two sustained yields units from the second level aggregation. The third level aggregation, (not shown) includes all 12 planning compartments.

per ha). Further, there is considerable pressure from rural communities and the forest industry to keep AAC's at historical levels, and when it is determined that harvests must decline (either the falldown effect or non-timber values, or a combination of the two) these groups require a transition period, such as the $10 \%$ decline per decade, to adjust plant capacity and local economies.

\section{Sustained yield units}

The TSA was first subdivided into 12 planning compartments, averaging 14745 ha (Fig. 3a). Each compartment contains approximately three watersheds averaging around 5000 ha. Individual watersheds were not modelled as sustained yield units for two reasons. First, the large number of watersheds in the TSA (at least 36) make this an onerous and impractical task, and second, clusters of about three watersheds typically have distinct geographic boundaries and form logical planning cells for administration purposes. Each of the 12 planning compartments was treated as a sustained yield unit during the harvest simulations. The harvest schedules from each unit were then summed to determine the total harvest for the TSA. This is referred to as the BASE case.
The next phase, referred to as the first level aggregation (FLA), involved combining three contiguous planning compartments to form four larger sustained yield units (Fig. 3b). For example, sustained yield unit one consists of planning compartments one to three. The average size of the sustained yield units in the FLA is $44250 \mathrm{ha}$. For each of these sustained yield units, harvest schedules were generated using the same periodic harvest flow constraints used in the BASE case. Periodic harvests from each of the FLA sustained yield units were then summed to find the harvest schedule for the TSA.

For the second level aggregation (SLA), two sustained yield units were constructed from six contiguous planning compartments (Fig. 3c). For example, SLA-1 consists of planning compartments one to six. Each of these larger sustained yield units represents approximately one-half of the TSA, and averages 88,750 ha. Again, 120-year declining-flow harvest schedules were generated for each sustained yield unit, and the results were summed to the TSA level.

Finally, for the third level aggregation (TLA), all 12 planning compartments were combined into a single sustained yield unit, representing the entire TSA (176944 ha). As with the other simulations, the TLA sustained yield unit was har- 


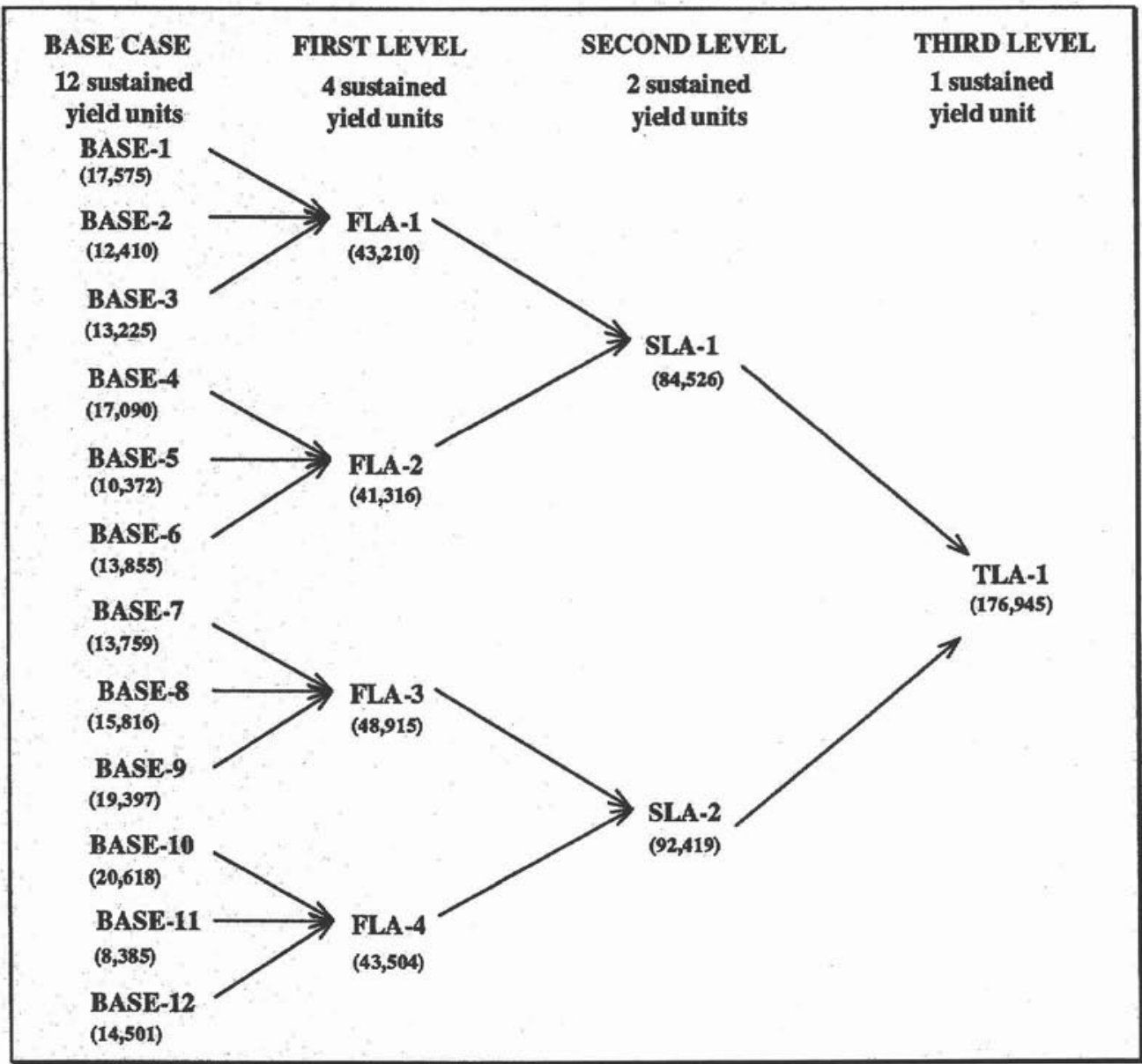

Figure 4. Steps in the aggregation process used to create the sustained yield units. The numbers in brackets are the total forested area of each sustained yield unit. vested using the 120-year declining-flow harvests specified in the previous aggregations. The steps involved in the aggregation process, and the area of each sustained yield unit are indicated (Fig. 4).

Once a feasible harvest schedule was generated for each sustained yield unit, the ATLAS model was used to generate a series of reports describing the harvests and related economic indicators. Periodic values were produced for the following indicators: 1) harvest area, 2) harvest volume, 3 ) delivered wood costs, and 4) length of active roads. In addition, the short- $(0$ 20 years $)$, medium- $(21-60$ years $)$, and long-term $(61-120$ years) averages for selected indicators were calculated at each level of aggregation.

Delivered wood costs are reported in $\$ / \mathrm{m}^{3}$, as are the sums of the logging, road construction, road maintenance, and hauling costs. When the delivered wood costs were calculated for aggregated compartments, a volume-weighted average was used.

\section{Results and Discussion}

Overall, the results demonstrate expected trends as sustained yield units increase in size. In general, the area and volume harvested increase as management unit size increases, while delivered wood costs decrease and active road lengths decrease. Between successive levels of aggregation, the trends for area and volume are strong, while the trends for delivered wood costs and active road lengths are not so well-defined. Each of these indicators are analyzed below.

\section{Harvest Area}

Summary statistics for harvest areas and volumes resulting from the aggregation process are presented (Fig. 5 and Table 2).

As shown (Fig. 5), the area harvested increases as the size of the sustained yield units increases. The larger units afford more options when adjacency constraints and green-up requirements lead to gridlock problems. The short-term increase in harvested area translates directly to an increase in harvested volume, particularly for the SLA and TLA aggregations, where the harvested area increases by $10 \%$ or more. Increases persist throughout the medium- and long-terms for all levels of aggregation, indicating that benefits can be realized far into the future. This is most likely due to the difficulty in breaking free from the rigid landscape pattern established by the adjacency rule. This pattern tends to repeat itself in subsequent harvests, and it can be very difficult to alter. Wallin et al. (1994) refer to this as "land-use legacies in forestry".

\section{Harvested Volume}

Summary statistics for the effects on harvest volumes resulting from the aggregation process are presented (Figure 6 and Table 3).

\section{(i) First Level Aggregation}

When compared to the sum of the BASE case, the FLAs showed a substantial increase in harvest volume. Overall harvest volumes increased from 21.0 $\mathrm{MM} \mathrm{m}^{3}$ to $22.1 \mathrm{MM} \mathrm{m}^{3}$ (Fig. 6). Of 


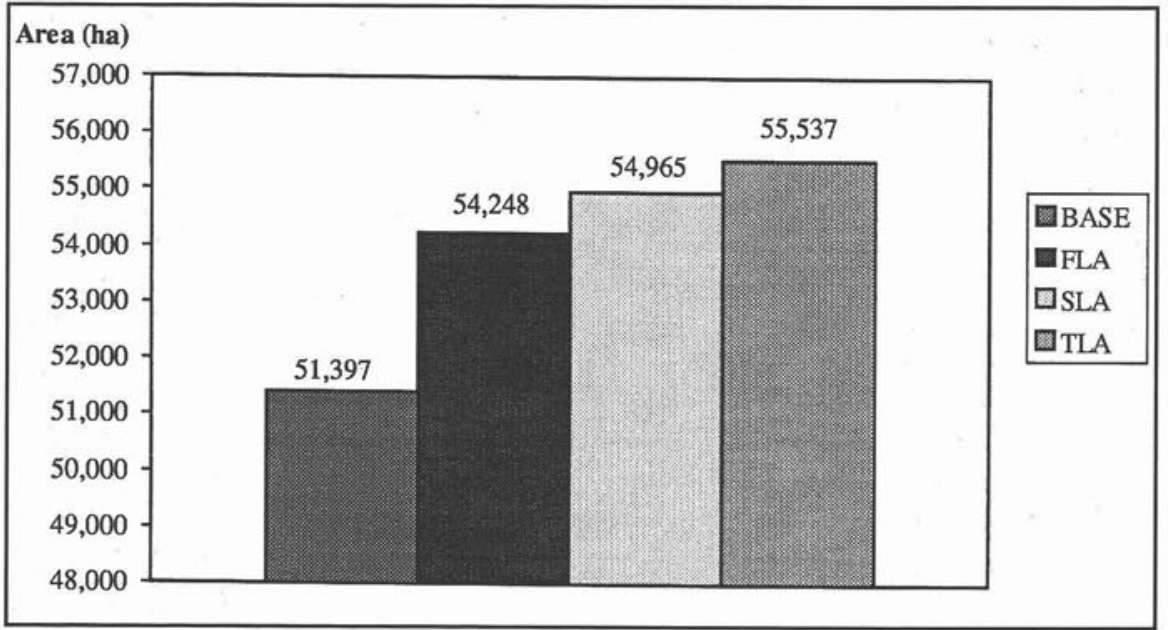

Figure 5. Total area harvested by sustained yield unit size. Total area harvested increases with sustained yield unit size.

Table 2. Percent change in the area harvested for all levels of aggregation, relative to the BASE case. The mean represents the sum of all sustained yield units, and the range shows the extremes observed in individual units

\begin{tabular}{lcccc}
\hline Unit & $\begin{array}{c}\text { Number of } \\
\text { units }\end{array}$ & $\begin{array}{c}\mathbf{0 - 2 0} \mathbf{~ y r} \\
\text { mean (range) }\end{array}$ & $\begin{array}{c}\mathbf{2 1 - 6 0} \mathbf{~ y r} \\
\text { mean (range) }\end{array}$ & $\begin{array}{c}\mathbf{6 - 1 2 0} \mathbf{~ y r} \\
\text { mean (range) }\end{array}$ \\
\hline FLA & 4 & $\mathbf{7 . 4}(5.7-13.9)$ & $\mathbf{5 . 4}(4.2-6.4)$ & $\mathbf{4 . 6 ( - 1 . 0 - 7 . 7 )}$ \\
SLA & 2 & $\mathbf{1 0 . 0}(9.4-10.3)$ & $\mathbf{7 . 6}(5.3-9.3)$ & $\mathbf{9 . 5}$ \\
TLA & 1 & $\mathbf{1 1 . 2}$ & $\mathbf{9 . 1}$ & $\mathbf{6 . 2}$ \\
\hline
\end{tabular}

the four FLA units created, short-term harvest volumes increased the most in FLA-one (12.5\%). The reason for this sizable increase can be attributed to the initial age-class profiles in the constituent planning compartments (one to three), as well as the high proportion of zones designated as visual and wildlife areas. When these BASE compartments were aggregated, the number of possible harvest locations increased, and gridlock problems caused by adjacency constraints and greenup requirements were alleviated. Increases remain positive throughout the remainder of the planning horizon, with medium- and long-term increases of $5.4 \%$ and $3.9 \%$ respectively. start

\section{(ii) Second Level Aggregation}

Increases in harvest volume for the second level aggregation surpassed those for the first level by only $135 \mathrm{M} \mathrm{m}^{3}$, yet when compared to the sum of the BASE planning compartments, the SLA yielded substantial increases in harvest volumes. Total harvest volumes increased from $21.0 \mathrm{MM} \mathrm{m}^{3}$ to $22.2 \mathrm{MM}$ $\mathrm{m}^{3}$ (Fig. 6). Short-term harvest volumes were similar for both the SLA compartments, however, medium- and long-term average increases were highest in SLA-two (10.2\%). This difference can be attributed to the initial age-class profiles in the two compartments - the south half of the TSA (SLA-one) having a longer history of harvesting than the northern half (SLAtwo). In addition, the high proportion of zones having a combination of visual and wildlife resource emphases in the southern half results in the deferral of mature blocks which must be retained to satisfy these landscape constraints. Substantial increases in harvest volumes persist throughout the remainder of the planning horizon (medium-term $=7.7 \%$, and longterm $=2.1 \%$ ), but decrease in magnitude as second rotation stands are harvested in the later periods. Interestingly, long-term timber supply in SLA-one is lower than when BASE com- partments one to six are treated as independent units (a reduction of $3.7 \%$ results from the aggregation). These long-term reductions in SLA-one are likely caused by the high harvest rates in the short-term, relative to the BASE case. Relative to SLA-one, the low, short-term harvest rates in the BASE case allows some stands to be postponed until the latter periods. The combination of beginning inventory and harvest contraints in the SLA-one aggregation results in an increase in short-term harvests, partly at the expense of long-term harvests.

\section{(iii) Third Level Aggregation}

The largest increase in harvest volume was obtained in the third level aggregation (TLA). Relative to the BASE case, harvest volumes increased from $21.0 \mathrm{MM} \mathrm{m}^{3}$, to $22.6 \mathrm{MM} \mathrm{m}^{3}$ (Fig. 6). Short-, medium-, and long-term harvest volumes increased by $10.8 \%, 8.8 \%$, and $5.5 \%$, respectively. The substantial increase in the long-term average may be a result of having achieved the harvest target during the early periods in planning compartments one to eight, thereby making planning compartments nine to twelve available during the later periods. In the third level aggregation, when the entire TSA is treated as the planning compartment, maximum scheduling flexibility is available, both in the short and long-term.

\section{Delivered Wood Costs}

Summary statistics for delivered wood costs $\left(\$ / \mathrm{m}^{3}\right)$ related to the aggregation process are presented (Fig. 7, Table 4).

Delivered wood costs (DWC) are not as clearly affected by sustained yield unit size as are the area and volume harvested. Short-term results indicate a slight reduction in DWC with increasing sustained yield unit size (Table 4). Medium-term results are fairly consistent, showing the most economically-sized unit to be the TLA, with a reduction of $\$ 0.21 / \mathrm{m}^{3}$. However, over the long-term, the FLA compartments have the lowest cost $\mathrm{m}^{-1}$ (\$0.95 
Figure 6. Total harvest volume by sustained yield unit size. Maximum harvest is achieved with the TLA, while the summation of the four FLA units or the two SLA units generate slightly lower total harvests. A significant decrease in harvest volume occurs when the 12 BASE compartments are treated as independent sustained yield units.

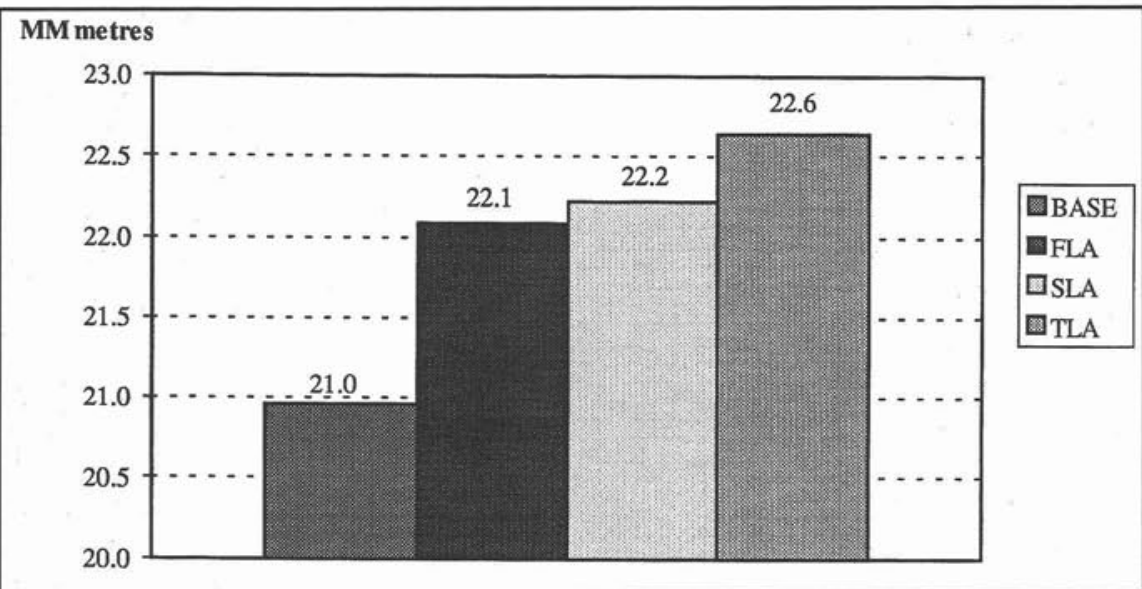

Table 3. Percent change in harvest volumes for all levels of aggregation, relative to the BASE case. The mean represents the sum of all sustained yield units, and the range shows the extremes observed in individual units

\begin{tabular}{|c|c|c|c|c|}
\hline Unit & $\begin{array}{c}\text { Number of } \\
\text { units }\end{array}$ & $\begin{array}{c}\text { 0-20 yr } \\
\text { mean (range) }\end{array}$ & $\begin{array}{c}21-60 \mathrm{yr} \\
\text { mean (range) }\end{array}$ & $\begin{array}{c}\text { 6-120 yr } \\
\text { mean (range) }\end{array}$ \\
\hline FLA & 4 & $7.6(5.3-12.5)$ & $5.4(4.1-7.3)$ & $3.9(-0.3-6.5)$ \\
\hline SLA & 2 & $\mathbf{1 0 . 0}(9.1-10.7)$ & $7.7(4.4-10.2)$ & $2.1(-3.7-7.1)$ \\
\hline TLA & 1 & 10.8 & 8.8 & 5.5 \\
\hline
\end{tabular}

$\mathrm{m}^{-3}$ reduction relative to the BASE case). These differences are mostly due to construction and maintenance of the road network.

Up to period seven, periodic changes in the delivered wood costs (relative to the BASE case) fluctuate between positive and negative for all levels of aggregation. This fluctuation is attributed to the adjacency constraints and the associated effect on the construction of the road network. In the initial period, the existing road network is exploited leading to low DWC. In the second period, adjacency constraints result in high levels of road construction as new areas are accessed. Harvesting in the third period exploits this recent construction, while the fourth period sees harvesting dispersed once again, along with increased road construction and maintenance costs. This cycle continues until the road network is fully constructed (approximately period eight), at which time the changes in DWC remain negative. The overall decrease in DWC resulting from aggregation is due to fewer active roads (less road maintenance costs) than in the BASE case where every planning compartment is active during every period.

\section{Active Roads}

Summary statistics for the length of active roads for all aggregation levels are shown (Fig. 8, Table 5).

Although active roads decrease substantially in the short-term, relative to the BASE case, the trend does not indicate a strong relationship to sustained yield unit size (Fig. 8). The short-term decrease in the average length of active roads can be mainly attributed to having achieved the target harvest levels in the first two periods without accessing all the planning compartments. Medium- and long-term trends, however, do show a recognizable trend towards having fewer kilometers of active roads in the larger sustained yield units. The inconsistency in the short-term is likely due to historical harvesting patterns and the transition from a historical three-pass harvesting system, to the four pass system dictated by the adjacency rules used in the simulations. Upon adoption of a four pass system, existing road networks must be rapidly expanded to satisfy the adjacency constraints. More consistent trends emerge once the entire road network has been established, and the transition period has passed.

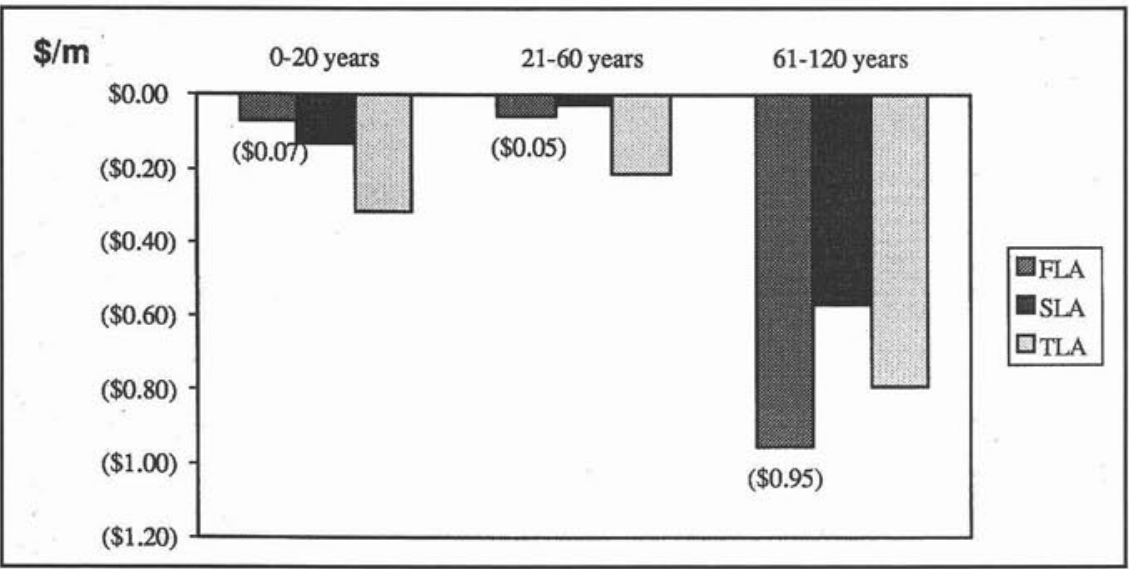

Figure 7. Change in delivered wood costs relative to the BASE case, for the short-, medium-, and long-term. 
Table 4. Changes in delivered wood costs $\left(\$ / \mathrm{m}^{3}\right)$ for all levels of aggregation, relative to the BASE case. The mean represents the sum of all sustained yield units, and the range shows the extremes observed in individual units

\begin{tabular}{lcccc}
\hline Unit & $\begin{array}{c}\text { Number of } \\
\text { units }\end{array}$ & $\begin{array}{c}\mathbf{0 - 2 0} \mathbf{~ y r} \\
\text { mean (range) }\end{array}$ & $\begin{array}{c}\mathbf{2 1 - 6 0} \mathbf{~ y r} \\
\text { mean (range) }\end{array}$ & $\begin{array}{c}\mathbf{6 - 1 2 0} \mathbf{~ y r} \\
\text { mean (range) }\end{array}$ \\
\hline FLA & 4 & $-\mathbf{0 . 0 7}(-.68-0.80)$ & $-\mathbf{0 . 0 5}(-0.54-0.44)$ & $-\mathbf{0 . 9 5}(-1.61-0.62)$ \\
SLA & 2 & $-\mathbf{0 . 1 3}(-0.14-0.13)$ & $-\mathbf{0 . 0 2}(-0.44--0.27)$ & $-\mathbf{0 . 5 7}(-0.63--0.59)$ \\
TLA & 1 & $-\mathbf{0 . 3 2}$ & $-\mathbf{0 . 2 1}$ & $-\mathbf{0 . 7 9}$ \\
\hline
\end{tabular}

\section{kilometers}

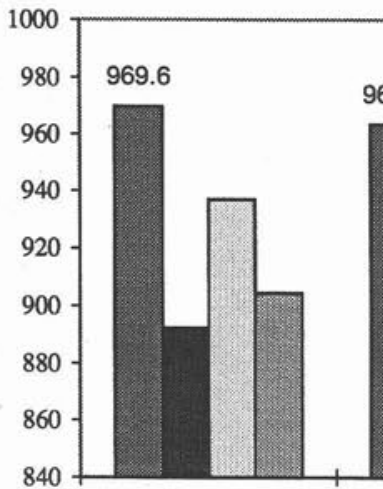

0-20 years

\section{4}

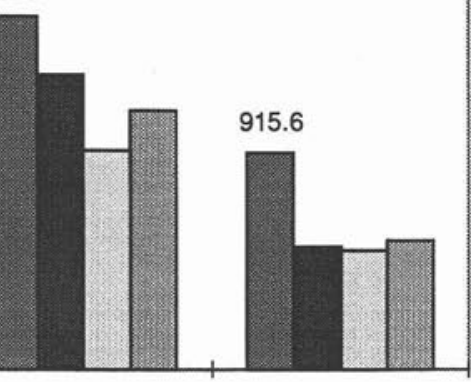

21-60 years

$61-120$ years

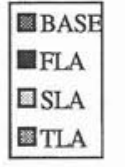

Figure 8. Short-, medium-, and long-term average lengths of active roads for all levels of aggregation. The BASE case results in substantially more active roads than does any other size of sustained yield unit. The relatively high short-term value for the SLA can be attributed to an abundance of immature timber in the southern part of the TSA.

Table 5. Percent change in length of active roads for all levels of aggregation, relative to the BASE case. The mean represents the sum of all sustained yield units, and the range shows the extremes observed in individual units

\begin{tabular}{lcccc}
\hline Unit & $\begin{array}{c}\text { Number of } \\
\text { units }\end{array}$ & $\begin{array}{c}\mathbf{0 - 2 0} \mathbf{y r} \\
\text { mean (range) }\end{array}$ & $\begin{array}{c}\mathbf{2 1 - 6 0} \mathbf{~ y r} \\
\text { mean (range) }\end{array}$ & $\begin{array}{c}\mathbf{6 - 1 2 0} \mathbf{~ y r} \\
\text { mean (range) }\end{array}$ \\
\hline FLA & 4 & $-7.7(-20.3--3.8)$ & $-2.0(-11.6--1.1)$ & $-3.8(-8.4--1.5)$ \\
SLA & 2 & $-3.1(-5.7--3.2)$ & $-4.9(-5.7--5.6)$ & $-\mathbf{3 . 9}(-1.3--9.5)$ \\
TLA & 1 & -6.5 & -3.1 & -3.2 \\
\hline
\end{tabular}

\section{Discussion}

Some generalizations can be made from the results. First, it appears that the maximum total harvested volume is realized when the TSA is managed for declining-flow harvests across its entirety. Second, the size of the sustained yield units can be decreased from the current size (176 945 ha. TSA) by a factor of four to the size of the sustained yield units represented by the first level aggregation (44 250 ha) without significant adverse impacts on volume flows, and without increasing the amount of active roads over the entire TSA. However, decreasing the size of the planning compartments beyond those in the FLA can result in significant negative impacts to short-term timber supply, and increase the amount of active roads on the landscape. Third, the increase in timber supply as a result of increasing the sustained yield unit size appears to persist throughout the planning horizon, a phenomena related to the inflexible landscape pattern created by adjacency constraints. Finally, a reduction in delivered wood costs and the abundance of active roads appears to have some relation to sustained yield unit size, but tends more to be sensitive to the spontaneous expansion of the road network resulting from the introduction of adjacency constraints.

Despite the low variation in total wood supply over the longterm, it is inevitable that within the short-term, some compartments will suffer immediate timber shortages. The severity of this shortage will of course depend on the current age-class structure of each unit and the harvest rules (Davis and Johnson 1987). This was true in our case in our study - in particular, BASE compartments two and seven have a history of high harvest rates, and hence the short-term timber availability in these units is low. Furthermore, the conversion from the historical three-pass harvesting system, to the four-pass system often results in an effective "gridlock" in the harvest schedule.

Obviously, the flexibility in harvest scheduling patterns afforded by the larger sustained yield units can help offset shortterm timber deficits, and avoid the occurrence of "gridlock" conditions. If one is prepared to relax the adjacency rules to relieve gridlock problems, the spatial model is very useful in identifying the offending harvest units.

Smaller sustained yield units will likely affect non-timber resources. Active roads and roaded areas, for example, are likely to be much more abundant across the landscape due to continuous harvesting in each small sustained yield unit. In this study, we reported the changes in active roads for the entire TSA. Although the total length of active roads decreased with increasing sustained yield unit size, periodic changes within certain watersheds were much more pronounced.

This temporal variation can be demonstrated by plotting the harvest activity in individual planning compartments when managed at two different levels of aggregation. The periodic harvest levels for BASE compartments one and ten when each is managed as an independent unit (BASE-1 and BASE-10), and 

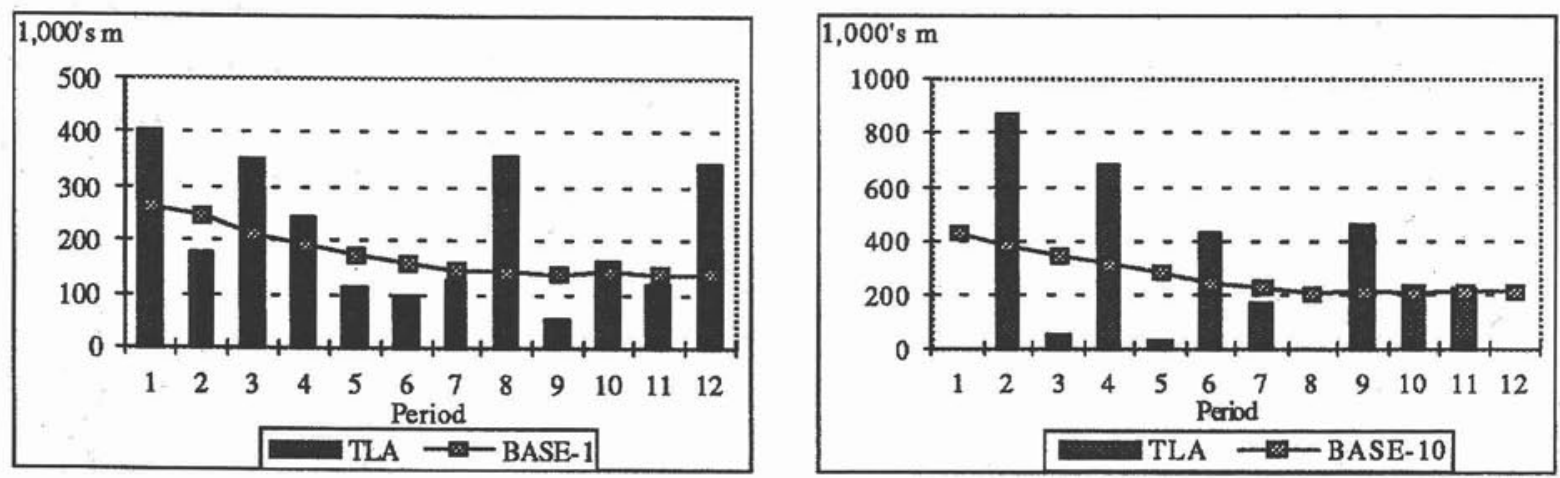

Figure 9. Comparison of harvest levels in compartments one and ten when scheduled as individual units (BASE) and as part of the entire TSA (TLA). Each schedule satisfies watershed level constraints, however, differences in intensity of harvest, and the length of the return interval are apparent.

when they both are included within the aggregated sustained yield unit for the entire TSA (TLA) is shown (Fig. 9). Recall that compartment one is located in the southern region of the TSA and has the highest harvest priority. Compartment ten, located in the northern region has a low harvest priority. Compartment one is subject to constant harvesting activity over the 120-year planning horizon, regardless of the size of the sustained yield unit. However, the intensity of harvest varies significantly when it is managed as part of the aggregated unit, TLA. When compartment ten is managed as part of the entire TSA, periods of high harvest intensity are followed by long intervals with little or no activity. This pattern contrasts strongly with the continuous harvest flow when compartment ten is managed as an independent unit. Which harvest flow pattern is preferable from a non-timber perspective is not clear. It can be argued that moderate, continuous harvests have low impacts on ecosystem health, or it can be argued that periods of heavy timber extraction, followed by long intervals of inactivity constitute a better practice (Hunter 1990). By specifying a minimum harvest level in each planning compartment, the TLA harvest levels shown (Fig. 9) could be altered to extend the return intervals. Minimum harvest levels were not specified in our study.

Most large ungulates, like moose and elk avoid areas with a high concentration of active logging roads (Rost and Bailey 1979; Ward 1975). For example, moose favour a heterogeneous mosaic of young and mature stand-types containing an abundance of early seral stands (Eastman 1978). These conditions would exist in the smaller planning compartments where harvesting is continuous, but essentially all the habitat is accessible. Woodland caribou, which prefer upslope habitats and reside in areas supporting an abundance of arboreal lichens (Stevenson and Hatler 1985) are highly migratory creatures and require suitable habitat over a large landbase. This condition could be created by managing large sustained yield units which allow harvests to be dispersed through a long periods of time, and across a large landbase. Combining long return intervals with appropriate road deactivation in individual watersheds, may provide better quality habitat and reduce harassment by humans (Stevenson and Hatler 1985).

While there may be preferences to restricted access for wildlife, there are economic and forest management concerns that favour a more accessible forest. Long return intervals and limited access with the presence of insects and disease increases the risk of catastrophic outbreaks. Pests endemic to the
Revelstoke TSA (spruce bark beetles and the hemlock looper) have caused substantial losses in the TSA during the past decade (BC Ministry of Forests 1986, 1993). Windthrow, fire, and root rot are other natural forces that create the need for salvage operations and accessibility throughout the TSA.

At the outset, the trend towards watershed level planning, and possible movement towards defining sustained yield units at this level was described. In this study watersheds were not modelled as sustained yield units because of the major work load this would entail. In the Revelstoke TSA, this could easily tally up to 36 units, creating an impractical workload for forest administrators. Defining even smaller sustained yield units will increase the number of harvest flow constraints across the TSA, and lead to even greater volume reductions than observed for the 12 planning compartments. In the long-term, smaller sustained yield units also imply an even greater level of continuous human activity throughout every watershed in the forest.

In some cases, local communities and industry have strong reasons for postponing immediate $\mathrm{AAC}$ reductions, and the shortterm harvests are maintained at historical levels and subsequently allowed to decline at rates greater than $10 \%$ per decade. In these circumstances, the flexibility offered by large sustained yield units would prove to be highly advantageous for meeting the immediate timber supply needs. If we had modelled these harvest flow constraints in our simulations, the increases in shortterm harvest levels associated with the larger units would probably have been greater.

Finally, the harvest rules, the initial age-class structure, and existing landscape patterns will strongly influence the results. More rigid rules, especially those controlling maximum disturbance rates and green-up ages, will tend to negate incremental gains related to larger units. When watersheds with deficits in the older age-classes and unfavourable landscape patterns are incorporated into large sustained yield units, significant incremental gains in short-term harvest levels will be realized.

\section{Conclusions}

Determining the ideal size of sustained yield units is a complex problem. Key factors are the harvest rules, harvest flow constraints, initial conditions of the forest, plus the timber and non-timber values desired. Specific to timber values in the Revelstoke TSA, the TSA could be partitioned into four sustained yield units (averaging 44250 ha) without causing 
serious reductions in timber supply or significant increases in delivered wood costs. Further aggregation to larger units produced only minor gains in harvest levels. Relative to the smallest sustained yield units, the larger units offer greater harvest scheduling flexibility, opportunities to concentrate harvesting operations in specific watersheds, and less administration in terms of determining AAC's. However, smaller management units may offer greater flexibility for salvaging damaged timber, and they to be appear environmentally friendly to the public eye. The effects of unit size on non-timber resources must also be given consideration, but here we have much to learn. With small units, non-timber resources may either be compromised, or benefit as sustainable harvests are implemented in watersheds throughout the forest. The impact of widely distributed, low intensity harvests (and active logging roads) on wildlife populations is a case in point. Further research in this area is critically needed. Another confounding problem is whether recreational opportunities will increase due to improved access, or decline because of the widely dispersed timber on the landscape. The effects of increased road construction and logging activity on water quality and fisheries values are also important factors to consider in the decision.

We have grown accustomed to the harvest scheduling flexibility afforded by an abundance of mature timber and large sustained yield units. Meanwhile, protection of non-timber resources and the transition to managed stands has placed downward pressures on AAC's. A multitude of regulations now control forest structure and landscape patterns in individual watersheds, and while these limit harvest scheduling flexibility, there are still gains, especially in the short-term, from scheduling harvests with large sustained yield units. This can help alleviate short-term timber supply problems, and with careful access management, it may be possible to minimize human impacts on wildlife.

\section{References}

BC Ministry of Forests. 1986. Forest insect and disease impacts in Timber Supply Areas. Pest Management Report \#6. Protection Branch, Victoria, BC. 43 p.

BC Ministry of Forests. 1991. Review of the timber-supply analysis process for BC timber supply areas. Victoria, BC. 43 p.

BC Ministry of Forests. 1993. Revelstoke TSA-Timber Supply Analysis. Integrated Resources Branch, BC Ministry of Forests. Victoria, BC. 60 p.

Davis, L.S. and K. N. Johnson 1987. Forest Management. Third Edition. McGraw-Hill, Inc. New York. 790 p.

Eastman, D.S. 1978. Habitat selection and use in winter by moose in sub-boreal forests of north central British Columbia and relationships to forestry. Ph.D. Thesis, Faculty of Forestry, University of British Columbia, Vancouver, BC.

Hunter, M. L. 1990. Wildlife, Forests, and Forestry. Principles of Managing Forests for Biological Diversity. Prentice Hall, Inc. New Jersey. 370 p.

Nelson, J. D., M. Hafer and T. Shannon. 1995. ATLAS: A Tactical Landscape Analysis System V1.3. User's Manual. Forest Operations Research Group, Department of Forest Resources Management. Faculty of Forestry, University of British Columbia. Vancouver, BC. 37 p.

Pearse, P. H. 1976. Timber rights and forest policy in British Columbia. 2 vols. Report of the Royal Commission on Forest Resources. Victoria, BC.

Rost, G.R. and J.A. Bailey. 1979. Distribution of mule deer and elk in relation to roads. Journal of Wildlife Management 43(3): 634-641. Stevenson, S.K. and D.F. Hatler. 1985. Woodland caribou and their habitat in southern and central British Columbia. Land Management Report, ISSN 0702-9861; no. 23. BC Ministry of Forests, Victoria, BC. 112 p.

Wallin, D.O., F.J. Swanson and B. Marks. 1994. Landscape pattern response to changes in landscape pattern generation: Land-use legacies in forestry. Ecological Applications 4(3) 569-580.

Ward, A.L. 1975. Elk behavior in response to timber harvest operations and traffic on the Medicine Bow Range in south-central Wyoming. In Proc. of the Elk-Logging-Roads Symp. Moscow, Idaho. pp. 32-43. 